\title{
Oscillatory pressure transients after flow interruption during bronchial challenge test in children
}

\author{
U. Frey, R. Kraemer
}

Oscillatory pressure transients after flow interruption during bronchial challenge test in children. U. Frey, R. Kraemer. CERS Journals Ltd 1997.

ABSTRACT: The measurement of the conventional interrupter resistance (Rint) is dependent on pressure equilibration between alveolar and airway opening pressure, which is often not achieved in the presence of severe airways obstruction or in small children. The damping properties $(d)$ of postocclusional oscillatory pressure transients after rapid flow interruption can be assessed independent of complete pressure equilibration, and we have previously shown them to be correlated to resistive properties of the respiratory system. We wanted to determine whether these transients were an expression of acoustic properties of the air in the airways, or whether they were caused by an interaction of gas and lung tissue, and whether $d$ was more sensitive than $R$ int to changes in airway mechanics.

Bronchial challenge tests were carried out with cumulative doses of inhaled carbachol in 10 healthy children (aged 7-14 yrs) and 50 asthmatic children (aged 5-15 yrs). The airflow interruptions were performed with a combined nebulizer-shutter head, allowing resistance measurements with each breath.

The frequency, and the damping factor of the postocclusional pressure transients changed significantly during carbachol challenge in both groups of children. The provocation dose (PD) at which the damping factor $(d)$ of the oscillatory pressure transients increased more than 2 SD above the baseline mean ("variancebased", PDvb) was lower than the PDvb of the end-interruption resistance (Rint,EI). These changes in frequency and damping factor were reversible after inhaling salbutamol.

These findings suggest that the damping properties of the postocclusional pressure transients after flow interruption can be used as a sensitive parameter to assess changes in airway mechanics during bronchial challenge test in children in whom pressure equilibration is frequently not achieved during airflow interruption due to airways obstruction.

Eur Respir J., 1997; 10: 75-81.
Division of Paediatric Respiratory Medicine, Dept of Paediatrics, University of Berne, Inselspital, Berne, Switzerland.

Correspondence: U. Frey

Division of Paediatric Respiratory Medicine Dept of Paediatrics

University of Berne

Inselspital

CH-3010 Berne

Switzerland

Keywords: Airway wall compliance asthmatic children

bronchial challenge interrupter technique oscillatory pressure transients respiratory impedance

Received: April 161996

Accepted after revision September 261996

Supported by Grant 32-25658.88 and 3230208.90 from the Swiss National Foundation for Scientific Research.
The interrupter technique [1-6] has been shown to be a simple noninvasive method of measuring changes in airway mechanics in children [7] or patients with limited co-operation. However, the reliability of the measurements of the interrupter resistance (Rint) has been questioned in severe airway obstruction or in small children with a generally higher airway resistance, since the measurement of $R$ int depends on complete pressure equilibration between alveoli and airway opening. Different techniques to analyse the airway opening pressure curve after flow interrupter have been proposed. A comparison of these analytical techniques by PHAGOO et al. [8] showed that the end-interrupter resistance (Rint,EI) reflects changes in lung mechanics most sensitively.

This Rint,EI is calculated from the airway opening pressure (time function) signal $P$ ao $\left(t^{\prime}\right)$ as follows: based on the assumption that, during a brief period $(100 \mathrm{~ms})$ of airflow interruption, rapid equilibration between alveolar pressure $(P \mathrm{~A})$ and airway opening pressure $(P \mathrm{ao})$ occurs, the Rint,EI is obtained by dividing the change in pressure $100 \mathrm{~ms}$ after interruption by the immediately preceding flow. An alternative method is the opening interrupter technique [6], which calculates the $R$ int,EI from the $P$ ao signal using a calibration resistance. Both techniques neglect the dynamic behaviour of pressure equilibration. The rise in pressure, $P$ ao $\left(t^{\prime}\right)$, is influenced by resistive, elastic and inertial properties of the respiratory system and can be described as follows: immediately after occlusion, there is a very rapid change in pressure (fig. 1), which has been thought to reflect only airway resistance (Raw). The first period is followed by highly damped oscillatory pressure transients and then by a slow rise in pressure. The latter has been ascribed both to stress relaxation in the thorax and pendelluft [3-5].

The postocclusional pressure transients were first described by SHEPARD [9] and JACKSON and co-workers [3]. In humans, it is not clear how these resonating pressure oscillations are generated. There is indirect evidence from the work of ROMERO et al. [10] and JACKSON and co-workers [11], in dog lung models, that there are similarities between the power spectrum of the oscillatory $P$ ao $\left(t^{\prime}\right)$ transients after flow interruption [10] and high 


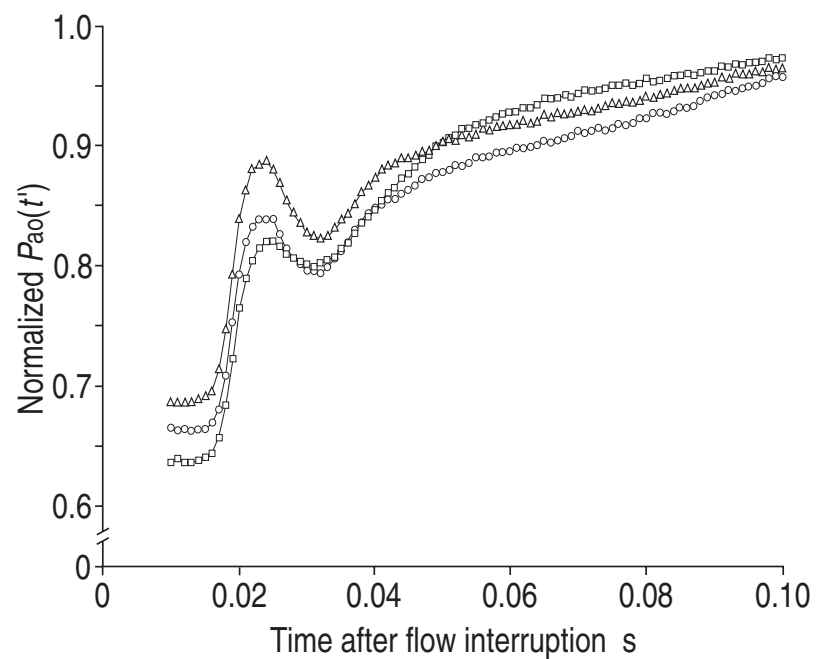

Fig. 1. - Normalized oscillatory airway opening pressure $P$ ao $\left(t^{\prime}\right)$ transients at baseline (- - ) , following bronchial challenge with 750 $\mathrm{ug}$ carbachol ( $\square-)$, and thereafter $800 \mu \mathrm{g}$ salbutamol $(-\Delta-)$ in a healthy 12 year old child.

frequency respiratory input impedance data ( $\left.Z_{\text {in }}\right)$ using forced oscillation technique [11]. Both in the power spectrum of $P$ ao $\left(t^{\prime}\right)$ after flow interruption and in the real part of the Zin, two relative maxima (antiresonances) can be detected. If measurements are performed using gases of lower density, the antiresonance at $\sim 180 \mathrm{~Hz}$ shifts to higher frequencies, whereas the antiresonance at $\sim 80 \mathrm{~Hz}$ does not change in dogs. This indicates that the resonance at $180 \mathrm{~Hz}$ is caused by an acoustic wave resonance of the gas in the airways, whereas the antiresonance at $80 \mathrm{~Hz}$ is independent of gas density and caused by the interaction of tissue inertia and gas compression [11]. In adult humans, JACKSON and co-workers [12] found only a single acoustic antiresonance and no tissue resonance. They suggested that the frequency of this acoustic antiresonance is dependent on airway wall compliance.

In our previous work, we also found only a single antiresonance in the power spectrum of $P$ ao $\left(t^{\prime}\right)[13,14]$. We have speculated that this single antiresonance is caused by an acoustic phenomenon of the air in the airways. We demonstrated that the damping properties of these oscillations are sensitive to airway mechanics, and change during bronchial challenge test in children $[13,14]$. This is especially interesting, since these oscillatory pressure transients are highly damped and independent of complete equilibration between alveolar and airway opening pressure.

As an extension of a previous study [14], we wanted to determine whether the frequency and the damping properties of the postocclusional pressure transients were more sensitive to changing lung mechanics during a bronchial challenge test in children than the conventional interrupter resistance.

\section{Materials and methods}

\section{Study subjects}

Ten healthy children ( 4 boys and 6 girls; mean age ( \pm SD) $9.9 \pm 2.0$ yrs, range 7-14 yrs) undergoing investi- gation for other purposes, and 50 children with atopic asthma (35 boys and 15 girls; mean age $8.3 \pm 2.8$ yrs, range 5-15 yrs) seen at the Paediatric Pulmonary Outpatient Clinic of the University Children's Hospital in Berne, Switzerland, were selected as study patients. Standardized case histories and physical examinations were performed by trained paediatricians in collaboration with the family doctor. Inclusion criteria were that the child was free from respiratory symptoms and had not had any signs of viral infections or vaccinations during the previous 6 weeks. Asthma was diagnosed by: a history of recurrent wheezy attacks; elevated immunoglobulin E (IgE) levels (paper radioimmunosorbent test (PRIST)); positive specific IgE (radioallergosorbent test (RAST)) for one or more allergens; and the documentation of airway obstruction (Raw), which reversed with sympathomimetics. At the time of testing, the patients were in a symptom-free interval, with no signs of asthma, and the last acute asthma episode was at least 2 weeks before examination. Bronchodilator treatment was withheld $12 \mathrm{~h}$ before and inhaled steroids or disodium cromoglycate $24 \mathrm{~h}$ before the test. None of the patients were on xanthine treatment, systemic steroids, or oral $\beta_{2}$-agonist. All of the subjects' parents gave their informed consent for the examinations and investigations, and the study was approved by the local Ethics Committee.

\section{Study design}

In healthy and asthmatic children, we determined whether the frequency and damping properties of the postocclusional pressure transients changed at lower provocation doses of carbachol than the end-interrupter resistance. After baseline lung function measurements (whole body plethysmography and interrupter technique), cumulative doses of inhaled carbachol were administered and the provocation dose at which each parameter changed significantly from the baseline mean was determined. Following this challenge, salbutamol was given in order to test the reversibility of the induced airway obstruction. For safety reasons, patients with airway resistance of more than $200 \%$ of the predicted value at baseline were excluded from the carbachol challenge (and therefore the study).

\section{Baseline lung function tests}

Functional abnormalities were evaluated by wholebody plethysmography using an air-conditioned, constant volume, variable pressure whole-body plethysmograph (Jaeger, Würzburg, Germany). The technique has been described previously [15]. Lung function data were expressed as a percentage of predicted values [16]. Functional residual capacity (FRC) at resting level was taken as an estimate of the degree of pulmonary hyperinflation, and $R$ aw as an estimate of the degree of bronchial obstruction.

\section{The interrupter technique}

The airflow interruptions were performed using the Bronchoscreen (Jaeger, Würzburg, Germany), a computerized apparatus with a combined nebulizer-shutter 
head, which enables changes in the resistance of the respiratory system (Rint,EI) to be measured with each breath. During quiet breathing, this technique uses the opening interrupter method to measure Rint,EI [6, 7]. The seated subject (with noseclip in place and the cheeks partly supported by a rubber mouthpiece) breathed air-conditioned ambient air to grow accustomed to the apparatus. The shutter closed within $15 \mathrm{~ms}$. The time of complete airflow interruption was $100 \mathrm{~ms}$. It was triggered 150 $\mathrm{ms}$ after the onset of the expiration. The dead space of the apparatus was $0.35 \mathrm{~L}$. The pressure transducer (Honeywell 142 PC 01G; Chesham, Bucks, UK) was connected via a side-port directly to the mouthpiece at a distance of $18 \mathrm{~cm}$ from the airway opening. Its frequency response was linear up to $400 \mathrm{~Hz}$. The influence of the mouthpiece on the postocclusional pressure transients has been described previously [14]. The signalto-noise ratio was less than $1 \%$, which includes the contribution of the mechanical action of the valve (vibrations of the slide valve). The interrupter signal was sampled in real time and analogue/digital converted with 12 bit accuracy at a sampling rate of $1,000 \mathrm{~Hz}$ by a Data Translation DT2811 converter (Data Translation, MA, USA). Fast Fourier Analysis was computed in realtime using a portable PC-system (Toshiba 3200, 80286/ Co87; Toshiba, Tokyo, Japan). The postocclusional pressure transients $P$ ao $\left(t^{\prime}\right)$ of the interrupter signal (fig. 1) were analysed in time domain (1st derivative $\mathrm{d} P$ ao $\left(t^{\prime}\right) / \mathrm{dt}$ of $P$ ao $\left.\left(t^{\prime}\right)\right)$ and frequency domain (Fourier analysis). The theory of mathematical analysis has been described previously $[13,14]$. The damping characteristics of the pressure oscillations seen were characterized by an exponential damping factor, $d$. Values between 0 (undamped) and 1 (critically damped) describe the degree of damping. The frequency $f^{\prime} F S$ was the frequency at the relative maximum in the power spectrum of $\mathrm{d} P$ ao $\left(t^{\prime}\right) / \mathrm{dt}$. Figure 1 shows an example of the postocclusional pressure transients at baseline, after carbachol and after salbutamol challenge in a 12 year old child.

\section{Bronchial challenge test}

Only the interrupter technique was performed during the challenge tests. Ten baseline measurements of $R$ int,EI, $d$ and $f^{\prime}$ FS were performed during inhalation of saline $(0.9 \%)$ from the in-built dosimeter. Carbachol chloride in saline buffered to $\mathrm{pH} 7.0$ with sodium bicarbonate (Merck Inc., Darmstadt, Germany), was used in a low concentration solution of $1.25 \mathrm{mg} \cdot \mathrm{mL}^{-1}$ during the first 10 breaths, and then in a higher concentration of $2.5 \mathrm{mg} \cdot \mathrm{mL}^{-1}$ until the end of the test procedure. This protocol was used for safety reasons to immediately detect children reacting to very low doses of carbachol. Generation time for aerosolization was $0.5 \mathrm{~s}$. Multiple nebulizer output measurements revealed a mean output of $44.1 \pm 5.5 \mu \mathrm{g}$ of solution per 10 breaths. Mean values of Rint,EI from five breathing cycles and a measure of $d$ and $f^{\prime}$ FS were calculated in relation to the cumulative dose at each level of carbachol. Special care was taken to increase the dose gradually to detect progressive small changes in Rint,EI. Using this procedure, a doseresponse curve was obtained and the provocation procedure was terminated when $R$ int,EI increased to $185 \%$ of the baseline value or earlier if symptoms occurred. We have chosen a relatively high provocation response $(185 \%)$, because we had rarely observed clinical symptoms in previous studies and wanted to ensure that all new parameters changed significantly. Thereafter, inhalation was switched to a bronchodilator administering $800 \mu \mathrm{g}$ salbutamol. Rint,EI, $d$ and $f^{\prime}$ 'FS were then reassessed.

\section{Statistical analysis}

Mean and standard deviation (SD) and coefficient of variation $(\mathrm{CV})$ were calculated from 10 baseline values prior to bronchial challenge. At every provocation level $(125,250,500,750$ and $1,000 \mu \mathrm{g}$ carbachol) averaged data were obtained from five flow interruptions for $R$ int,EI. To avoid a delay in provocation test time, only a single flow interruption for $d$ was performed per provocation dose, because we were limited by the sampling and analysing time. In this way, the time of the whole test was reduced to $2-4 \mathrm{~min}$, a period which was well tolerated by the small children. The so called "variance-based" provocation dose (PDvb) was calculated as described previously [7]. PDvb represents the lowest provocation dose at which a parameter exceeds the baseline mean +2 SD. This approach to defining the lowest levels of significant provocation was used for the target parameter Rint,EI, the damping factor $d$ and $f^{\prime}$ 'FS obtained from the analysis of the postocclusional pressure transients. The provocation doses calculated were called $\mathrm{PDvb}\left(R\right.$ int,EI), $\operatorname{PDvb}(d), \operatorname{PDvb}\left(f^{\prime} \mathrm{FS}\right)$. This statistical approach is only valid because all parameters were derived from the same physiological signal.

Cumulative sensitivity of a parameter (Rint,EI, $d, f^{\prime} \mathrm{FS}$ ) was defined by the number of subjects who showed a change of more than 2 SD from the baseline mean as a ratio of the total number of subjects in the group at each dose. From the maximal value following the carbachol challenge, the response to salbutamol was calculated for Rint,EI, $d, f^{\prime}$ FS expressed in standard deviation (of baseline mean). Since data were not normally distributed after carbachol challenge, the response to salbutamol was expressed as group median and range.

\section{Results}

\section{Biometric data and baseline measurements}

Age, sex-distribution and the baseline values of lung function, including $R$ int,EI(bl), $d$ and $f^{\prime}$ FS of the 10 healthy and 50 asthmatic children are summarized in table 1. In general, the intrasubject variability of the 10 baseline measurements was higher in the healthy than in the asthmatic subjects. Relationships between Rint,EI(bl), $d$ and $f^{\prime} \mathrm{FS}$ and plethysmographic data have been described previously [13].

\section{Change of resonance frequency during bronchial chal- lenge test}

The antiresonance frequency, $f^{\prime} \mathrm{FS}$, changed inconsistently during the carbachol challenge test. In 12 subjects, $f^{\prime} \mathrm{FS}$ increased from baseline value, in 31 children 
Table 1. - Age, sex-distribution and baseline values of lung function, including Rint,El (bl), $d$ and $f^{\prime}$ FS of the healthy and asthmatic children

\begin{tabular}{|c|c|c|c|c|c|c|c|c|c|c|}
\hline Ss & $\mathrm{n}$ & $\begin{array}{l}\text { Sex } \\
\mathrm{M} / \mathrm{F}\end{array}$ & $\begin{array}{l}\text { Age } \\
\text { yrs }\end{array}$ & $\begin{array}{c}\text { FRC } \\
\mathrm{L}^{*}\end{array}$ & $\begin{array}{c}\text { FRC } \\
\% \text { pred* }\end{array}$ & $\begin{array}{c}R \text { aw } \\
\mathrm{kPa} \cdot \mathrm{L}^{-1} \cdot \mathrm{s}^{*}\end{array}$ & $\begin{array}{c}R \text { aw } \\
\% \text { pred* }\end{array}$ & $\begin{array}{l}R \text { int,EI (bl) } \\
\mathrm{kPa} \cdot \mathrm{L}^{-1} \cdot \mathrm{s}^{\#}\end{array}$ & $\begin{array}{c}d \\
\text { ration }\end{array}$ & $\begin{array}{l}f^{\prime} \mathrm{FS} \\
\mathrm{Hz}^{\#}\end{array}$ \\
\hline Healthy & 10 & $4 / 6$ & $\begin{array}{r}9.9 \\
\pm 2.0\end{array}$ & $\begin{array}{r}1.51 \\
\pm 0.36\end{array}$ & $\begin{array}{r}97 \\
\pm 21\end{array}$ & $\begin{array}{r}0.34 \\
\pm 0.12\end{array}$ & $\begin{array}{r}102 \\
\pm 34\end{array}$ & $\begin{array}{rr}0.53 & (10.3) \\
\pm 0.13 & (8.3)\end{array}$ & $\begin{array}{r}0.45(8.5) \\
\pm 0.14(3.5)\end{array}$ & $\begin{array}{l}56.1(4.2) \\
\pm 8.8(3.9)\end{array}$ \\
\hline Asthmatic & 50 & $35 / 15$ & $\begin{array}{r}8.3 \\
\pm 2.8\end{array}$ & $\begin{array}{c}1.44 \\
\pm 0.434\end{array}$ & $\begin{array}{l}104 \\
\pm 28\end{array}$ & $\begin{array}{r}0.51 \\
\pm 0.23\end{array}$ & $\begin{array}{l}133 \\
\pm 54\end{array}$ & $\begin{array}{r}0.77 \\
\pm 0.29 \quad(6.9)\end{array}$ & $\begin{array}{r}0.51(6.6) \\
\pm 0.11(2.8)\end{array}$ & $\begin{array}{l}52.6(7.2) \\
\pm 7.9(5.3)\end{array}$ \\
\hline
\end{tabular}

*: Mean $\pm \mathrm{SD}$; \#: baseline mean $\pm \mathrm{SD}$, and coefficient of variation $(\%)$ in parenthesis, of 10 measurements of the end-interrupter resistance $(R$ int,EI $(\mathrm{bl}))$, damping factor $(d)$ and frequency $\left(f^{\prime} \mathrm{FS}\right)$ of the postocclusional oscillatory pressure transients after flow interruption. Predicted values from reference values of ZaPLETAL et al. [16]. Ss: subjects; M: male; F: female; FRC: functional residual capacity; Raw: airway resistance; \% pred: percentage of predicted value.

Table 2. - Number of patients per group in which the frequency of the postocclusional pressure transient ( $f^{\prime} \mathrm{FS}$ ) changed more than 2 SD after bronchial challenge

\begin{tabular}{|c|c|c|c|c|c|c|c|}
\hline \multirow[t]{2}{*}{ Group } & \multirow[t]{2}{*}{$\mathrm{n}$} & \multicolumn{3}{|c|}{ Carbachol } & \multicolumn{3}{|c|}{ Salbutamol } \\
\hline & & + & $\mathrm{NC}$ & - & + & $\mathrm{NC}$ & - \\
\hline Healthy & 10 & 2 & 4 & 4 & 6 & 2 & 2 \\
\hline Asthmatic & 50 & 10 & 27 & 13 & 13 & 29 & 8 \\
\hline
\end{tabular}

+: increase; -: decrease; NC: no change.

it did not change significantly, and in 17 children it decreased significantly (table 2 ). There was no correlation between the behaviour of $f^{\prime}$ FS during the carbachol challenge and age, length, baseline airway resistance or FRC, but children with increased $f^{\prime}$ 'FS during the carbachol challenge test had significantly lower baseline values for $f^{\prime} F S$ (fig. 2; $<<0.001$ (Wilcoxon test)) than children with unchanged or decreased $f^{\prime}$ 'FS.

In the group of 29 children in which we observed a significant change in $f^{\prime}$ 'FS after carbachol, 18 normalized after salbutamol challenge, i.e. the value of $f^{\prime} \mathrm{FS}$

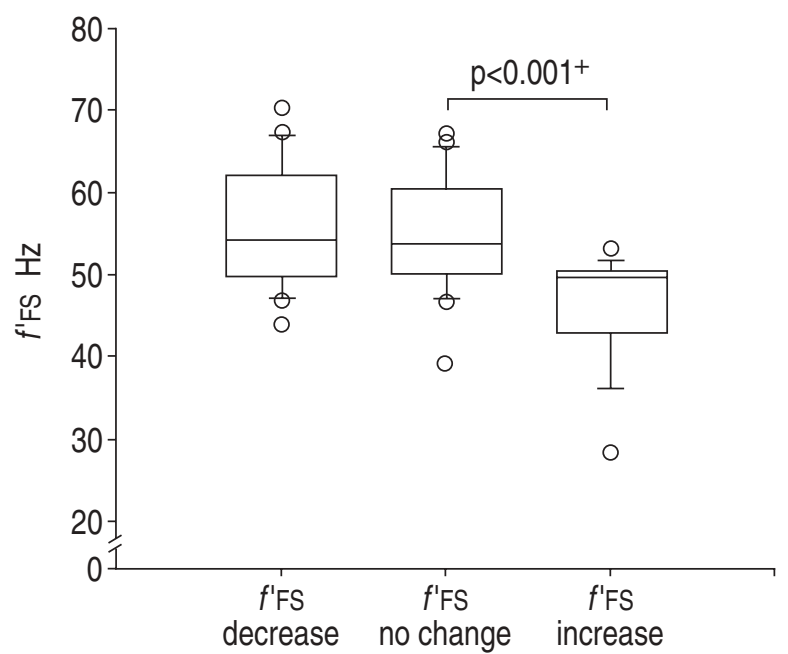

Fig. 2. - Frequency at the relative maximum in the power spectrum $\left(f^{\prime} \mathrm{FS}\right)$ at baseline in three groups, according to changes induced by carbachol. Whether $f^{\prime}$ 'FS decreased, increased or did not change after carbachol challenge was dependent on the absolute value of $f^{\prime} F S$ at baseline. Groups are represented as mean and unequal variances. While this pattern could be explained by the frequency dependence of wave propagation velocity in compliant tubes, statistical regression to the mean has to be considered as a potential error (see Discussion). ${ }^{+}$: Wilcoxon test. after salbutamol was within the range of the baseline mean \pm 2 SD. In six children, we found a partial normalization and in five children we found $f^{\prime}$ FS values that were, paradoxically, more deviated from baseline than after the carbachol challenge.

\section{Sensitivity of the damping factor in comparison to the Rint,EI}

In figure 3 , the dynamics of $R$ int,EI and $d$, obtained at baseline and at each provocation level with carbachol $(125,250,500,750$ and $1,000 \mu \mathrm{g})$ are presented. During bronchial provocation test $R$ int,EI and $d$ increased in healthy and asthmatic children. The increase in $d$ reflects an increase in damping of the postocclusional pressure transients. Both in healthy and asthmatic children, $d$ detected significant changes after carbachol at lower doses than the Rint,EI (fig. 3 ). If the asthmatic children were divided into children with airway obstruction (Raw $>130 \%$ pred) and a group with pulmonary hyperinflation (FRC $>130 \%$ pred) at baseline, there was no difference regarding the behaviour of $d$ and $R$ int,EI during the carbachol challenge test, therefore these results are not shown graphically. After the methacholine challenge

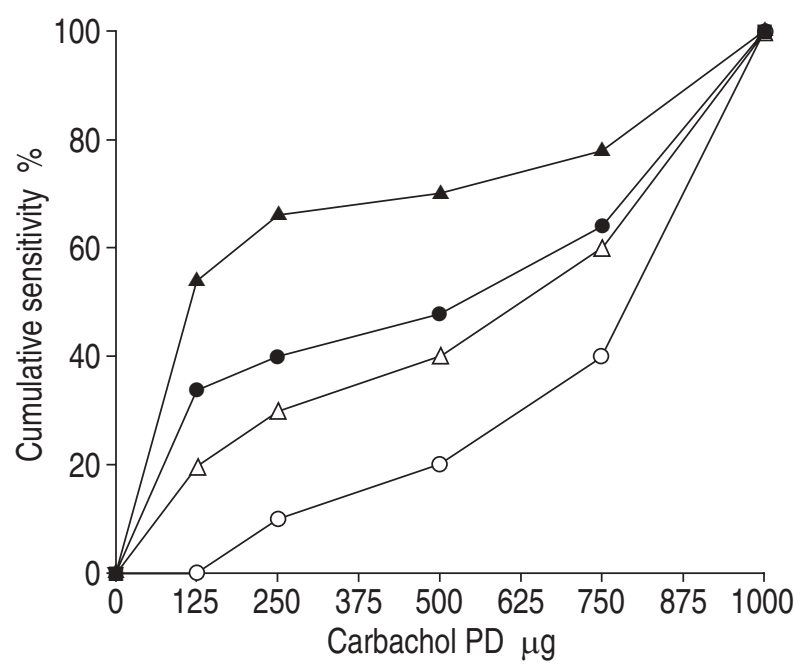

Fig. 3. - Cumulative increase of the sensitivity for Rint,EI and $d$ during bronchial challenge tests with carbachol in 10 healthy and 50 asthmatic children. $d$ reflected changes in airway mechanics at lower provocation doses (PDs) than did Rint,EI. - - - : end-interrupter resistance $(R \mathrm{int}, \mathrm{EI})$, asthmatic group; - - - $R$ int,EI, healthy group; $-\mathbf{\Lambda}-$ : damping factor $(d)$, asthmatic group; $-\Delta-d$, healthy group. 
test, $800 \mu \mathrm{g}$ of salbutamol was administered. After salbutamol, $d$ improved in the healthy group (group median $8.1 \mathrm{SD}$; range 2.91-22 SD) and in the asthmatic children (group median 6.22 sD; range $0.3-30 \mathrm{SD}$ ), whereas $R$ int,EI improved in the healthy group (group median 1 SD; range -14-24 SD) and in the asthmatic group (group median 2.3 SD; range -6.12-28.3 SD). Negative values represent higher Rint,EI after salbutamol, found in seven subjects.

\section{Discussion}

This methodological study was undertaken to determine whether the damping properties of postocclusional pressure transients after rapid flow interruption changed significantly during bronchial challenge test and might, therefore, be an expression of airways obstruction. Firstly, the frequency of the postocclusional pressure transients changed after bronchial challenge in children, independent of age, weight, height, airway resistance or FRC at baseline However, the children who had an increase in frequency of the postocclusional oscillatory pressure transients during bronchial challenge had significantly lower values of $f^{\prime} \mathrm{FS}$ at baseline. The change in $f^{\prime} F S$ was at least partly reversible after salbutamol in most of the children. Secondly, the damping properties of the postocclusional pressure transients after flow interruption changed significantly during bronchial provocation test with carbachol and salbutamol. For healthy and asthmatic children, the damping properties of the postocclusional pressure transients changed at lower provocation doses than the Rint,EI, which was known to be the most sensitive indicator of the interrupter curve during bronchial challenge test in children [8].

\section{The nature of the postocclusional pressure transients}

The frequency and damping properties of the airway opening pressure oscillations were first described by SHEPARD [9] and JACKSON et al. [3] in humans in time domain using a resistance, compliance, inertia (RCI) model, and by Romero et al. [10] in frequency domain in tracheotomized dogs.

ROMERO et al. [10] found an antiresonance peak in the power spectra at $\sim 80 \mathrm{~Hz}$, which was considered to be due to the interaction of gas compliance and tissue inertance, and a peak at $\sim 150 \mathrm{~Hz}$, which represented the quarter-wave acoustic resonance of air in the airway. ROMERO et al. [10] based his assumption on the similarity of the power spectrum of the postocclusional pressure transients after flow interruption and the respiratory impedance spectrum measured by forced oscillatory technique, as described by JACKSON and LUTCHEN [11] in dogs. The antiresonance at $80 \mathrm{~Hz}$ can be explained by a lumped parameter model [17], which assumes that airway properties and lung tissue properties are lumped together in series and thoracic gas compliance is reflected by a parallel shunt element. The lumped parameter model cannot explain the antiresonance that occurred at $150 \mathrm{~Hz}$ in dogs because its frequency depends on gas density [11]. This antiresonance phenomenon is, therefore, an acoustic antiresonance. The frequency of such an acoustic resonance only depends on gas density, the wave propagation velocity in the tube and the tube length [18]. The propagation velocity of the travelling pressure wave in a compliant tube is a function of the tube wall compliance [18]. The frequency of the acoustic antiresonance is, therefore, a function of the airway wall compliance.

The situation in humans seems to be different, as described by JACKSON and co-workers [12] using the forced oscillation technique. In human adults, they found only a single antiresonant frequency in the respiratory input impedance spectrum at $\sim 180 \mathrm{~Hz}$ and identified it as an acoustic antiresonance, because its frequency increased during $\mathrm{He} / \mathrm{O}_{2}$ gas mixture breathing. In previous work, we also only found a single antiresonant frequency using the interrupter technique $[13,14]$, and speculated that it is an acoustic resonance phenomenon. However, the absolute value of $f^{\prime}$ FS which we found was lower than that reported by JACKSON and co-workers [12], because the length of the mouthpiece contributes to $f^{\prime} F S$ if it is calculated from the power spectrum analysis of postocclusional pressure transients after flow interruption [14].

The behaviour of the antiresonance frequency during a carbachol challenge test was very heterogeneous between the different individuals, but in half of the children we were able to measure significant changes in $f^{\prime}$ FS. Based on evidence from the previous studies mentioned above, we will discuss our findings with respect to an acoustic antiresonance model. Since it is very unlikely that the length of the airways changes during carbachol challenge test, changes of $f^{\prime} \mathrm{FS}$ are probably correlated to changes in airway wall compliance. The relationship between the acoustic resonant frequency and airway wall properties is very complex. The acoustic resonance frequency is correlated with the propagation velocity in a compliant tube [18]. The faster the pressure wave travels, the higher the resonance frequency. The wave propagation velocity in a compliant tube is frequency-dependent [18], and this frequency dependence is not a linear function (fig. 4). We assumed that during carbachol challenge the airway smooth muscle was likely to increase its tone, and, therefore, the airway wall compliance would decrease. If the frequency at baseline is in sector 1 , the wave propagation velocity is likely to increase during the challenge $(\mathrm{C} \rightarrow$ $\left.\mathrm{C}^{\prime}\right)$. If it is between sector 1 and 2 it is unlikely to change and if it is in sector 2 it is likely to decrease during the carbachol challenge. Since we found that $f^{\prime}$ FS was significantly lower in the group of children who increased $f^{\prime} \mathrm{FS}$ during the challenge, it is tempting to speculate that $f^{\prime}$ FS must have been in sector 1 in this group, between 1 and 2 in the group in which $f^{\prime}$ FS did not change, and in sector 2 in the group in which $f^{\prime} F S$ decreased. Unfortunately, the physiological model is highly frequency dependent and $f^{\prime} F S$ can increase or decrease during the challenge test. Therefore, we are unable to make a reliable distinction between a true physiological change in airway wall properties and a statistical regression to the mean. We speculate from the data, that, if $f^{\prime} F S$ represents the frequency of an acoustic antiresonance phenomenon, changes in $f^{\prime}$ FS during carbachol might be an expression of changing airway wall properties. 


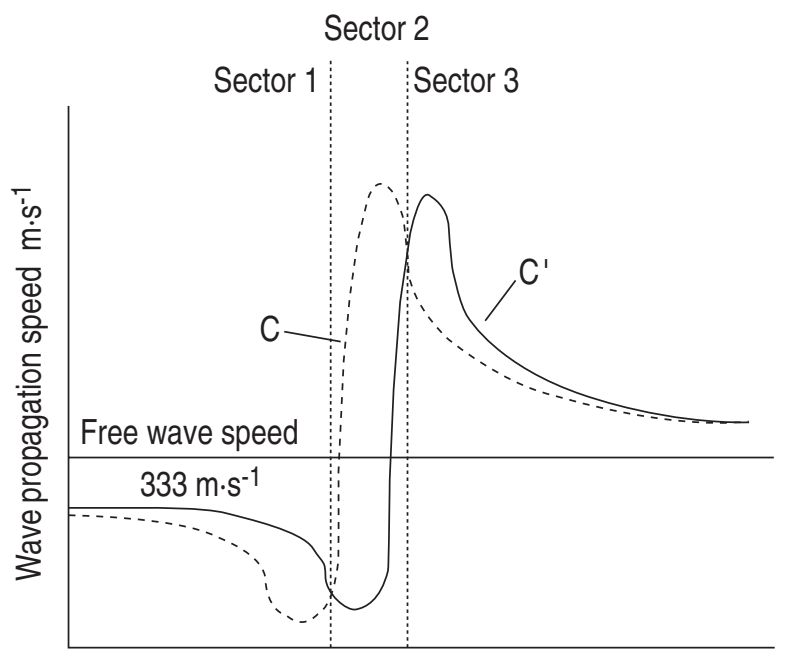

Frequency of the propagating wave $\mathrm{Hz}$

Fig. 4. - Schematic wave propagation velocity as a function of frequency of the travelling pressure wave in a more $(\mathrm{C})$ and less compliant tube $\left(\mathrm{C}^{\prime}\right)$. We assume that during bronchial challenge airway smooth muscle tone increases and airway becomes stiffer $\left(\mathrm{C}->\mathrm{C}^{\prime}\right)$. (Adapted from [18]).

The limits of the method can be described as follows. The physiology of the acoustic antiresonance phenomenon has been discussed because of the likely similarity of the power spectrum of postocclusional pressure transients after flow interruption and high frequency input impedance measurements $[10,13,14]$. However, the antiresonance phenomenon in the power spectrum of the postocclusional pressure transients cannot strictly be compared to the antiresonances which occur in the impedance spectrum using the forced oscillation technique, because in the forced oscillation technique both oscillatory flow and oscillatory pressure are measured. Using the interrupter technique with a single airway opening pressure channel, the absolute value of the frequency of the acoustic antiresonance is influenced by the length of the mouthpiece up to the shutter [14]. However, relative changes during carbachol challenge should not be crucially influenced by this fact, because the mouthpiece remains constant. The speed of the shutter closure mainly influences the amplitude of the antiresonance [10]. The limitations of this study show that, in future studies, acoustic resonance phenomena in the respiratory system should be modelled using more sophisticated lung models, for example distributed parameter models [19], which could provide a reliable parameter for airway wall compliance. In order to do so, it would be necessary to measure not only the oscillatory pressure, but also the resulting oscillatory flow, and to calculate high frequency respiratory input impedance [19].

\section{The damping properties of the postocclusional pressure transients}

We previously showed that the damping properties of the postocclusional pressure transients increased with increasing airway obstruction [14]. This is reflected by an increase in the exponential damping factor, $d$. We found that $d$ changed significantly during the carbachol challenge in healthy and in asthmatic children. We cannot exclude the possibility of changes in lung volume during carbachol challenge test. However, we would expect pulmonary hyperinflation rather than deflation during a carbachol challenge. We have shown, in a previous study [14], that the damping factor is lower at higher lung volumes, therefore an increase in $d$ during a carbachol challenge is more likely to be associated with airway obstruction. The value of $d$ changed at even lower provocation doses than $R$ int,EI. It also significantly reflected changes in airway mechanics after salbutamol challenge. Since PHAGOO et al. [8] showed previously that the $R$ int,EI reflects the changes in airway mechanics with the most sensitivity of any of the parameters of the interrupter curve in children, we conclude that the damping factor, $d$, reflects changes in airway mechanics more sensitively, even at lower provocation doses. This makes the provocation test safer and more comfortable. Furthermore $d$ is not dependent on the complete pressure equilibration between alveolar and mouth pressure, which was always an important limitation of the interrupter technique in the past.

\section{Conclusion}

We examined whether frequency and damping properties of the postocclusional oscillatory pressure transients after airflow interruption were useful in describing airway mechanics in children during bronchial challenge. We found that the frequency of these oscillations changed during carbachol challenge. The behaviour of this frequency during carbachol and salbutamol challenge is highly complex. We proposed an acoustic antiresonance model to explain the changes in frequency due to changes in airway wall properties. However, the current study shows that changes in the frequency of the postocclusional pressure transients cannot be satisfactorily explained by changes in airway wall compliance, since they are so complex that they cannot be distinguished from simple regression to the mean.

We propose that, for future studies of airway wall properties, more sophisticated distributed model analysis of high frequency impedance data requiring the additional assessment of oscillatory flow, should be used. Since airway wall compliance and stability are important factors in the understanding of flow limitation and wheezing disorders, especially in young children and infants [20], we would like to stress the need for such future studies. Nevertheless, the current study showed that the simple analysis of the damping properties of the postocclusional pressure transients is empirically important, since they are more sensitive to changes in airway mechanics during carbachol challenge in children than the end-interrupter resistance, and because they are independent of complete equilibration between alveolar and mouth pressure, a fact that limited the interrupter technique in the past. The clinical importance of the interrupter technique is based on its noninvasiveness and the fact that it does not require the co-operation of the subjects. This makes it particularly interesting in patients with limited co-operation, such as preschool children. 


\section{References}

1. von Neergaard K, Wirz K. Die Messung der Strömungswiderständen in den Atemwegen des Menschen, insbesondere bei Asthma und Emphysem. Z Clin Med 1927; 105: 51-82.

2. Mead J, Whittenberger JL. Evaluation of the airway interruption technique as a method for measuring pulmonary airflow resistance. J Appl Physiol 1954; 6: 408-416.

3. Jackson AC, Milhorn HT, Norman JR. A re-evaluation of interrupter technique for airway resistance measurements. J Appl Physiol 1974; 36: 264-268.

4. Bates JHT, Ludwig MS, Sly PD, Brown K, Martin JG, Fredberg JJ. Interrupter resistance elucidated by alveolar pressure measurements in open chest normal dogs. J Appl Physiol 1988; 65: 408-414.

5. Bates JHT, Baconnier P, Milic-Emili J. A theoretical analysis of interrupter technique for measuring respiratory mechanics. J Appl Physiol 1988; 64: 2204-2214.

6. Van der Plas K, Vooren P. The opening interruptor: a new variant of a technique for measuring respiratory resistance. Eur J Respir Dis 1982; 63: 449-458.

7. Wirz Sommer C, Frey U, Schöni HM, Kraemer R. Specific approach on dose-response curves to inhaled carbachol assessed by the interruption technique in children. Pediatr Res 1993; 34: 478-484.

8. Phagoo SB, Watson RA, Pride NB, Silverman M. Accuracy and sensitivity of interrupter technique for measuring the response to bronchial challenge in normal subjects. Eur Respir J 1993; 6: 996-1003.

9. Shepard RJ. Mechanical characteristics of the human airway in relation to use of the interrupter valve. Clin Sci (Lond) 1963; 25: 263-280.

10. Romero PV, Sato J, Shardonofsky F, Bates JH. High frequency characteristics of respiratory mechanics determined by flow interruption. J Appl Physiol 1990; 69: $1682-1688$.

11. Jackson AC, Lutchen KR. Modelling of respiratory system impedances in dogs. J Appl Physiol 1987; 62: 414-420.

12. Jackson AC, Giurdanella CA, Dorkin HL. Density dependence of respiratory system impedances between 5 and $320 \mathrm{~Hz}$ in humans. J Appl Physiol 1989; 67: 2323-2330.

13. Frey U, Kraemer R. Interrelationship between postocclusional oscillatory pressure transients and standard lung function in healthy and asthmatic children. Ped Pulmonol 1995; 19: 379-388.

14. Frey U, Schibler A, Kraemer R. Pressure oscillations after flow interruption in relation to lung mechanics. Respir Physiol 1995; 102: 225-237.

15. Kraemer R, Meister B, Schaad UB, Rossi E. Reversibility of lung function abnormalities in children with perennial asthma. J Pediatr 1983; 102: 347-350.

16. Zapletal A, Samanek M, Paul T. Lung function in children and adolescents: methods, reference values. Prog Respir Res 1987; 22: 113-218.

17. DuBois AB, Brody AW, Lewis DH, Burgess BF Jr. Oscillation mechanics of lung and chest in man. J Appl Physiol 1956; 8: 587-594.

18. Guelke RW, Bunn AE. Transmission line theory applied to sound wave propagation in tubes with compliant walls. Acustica 1981; 48: 102-107.

19. Jackson, AC, Suki B, Ucar M, Habib RH. Branching airway-network models for analyzing high frequency lung input impedance. J Appl Physiol 1993; 75: 217-227.

20. Prendiville A, Green S, Silverman M. Paradoxical response to nebulized salbutamol in wheezy infants, assessed by partial expiratory flow volume curves. Thorax 1987; 42: 86-91. 